\title{
El mercado de seguros en Cuba, siglo XIX*
}

\author{
por
}

\author{
Rosell Cruz Pasos ${ }^{1}$
}

Investigador independiente

\begin{abstract}
El presente artículo evidencia la existencia de un mercado de seguros en La Habana durante el siglo XIX, integrado por 78 compañias de seguros que especularon en esta plaza: 36 españolas (61\% fundadas en La Habana) y 42 extranjeras, lo que duplica la cantidad anteriormente reportada. El estudio se ha sustentado en una revisión exhaustiva de documentos publicados mientras ocurrían los acontecimientos narrados: los datos oficiales remitidos al Ministerio de Ultramar o las normas jurídicas emitidas por la administración de la isla. También en obras posteriores que tratan acontecimientos que tuvieron influencia sobre el desarrollo de la industria azucarera y el comercio en la isla. Desarrollo que impulsó, a su vez, la necesidad de utilizar el seguro para afianzar aquella aventura económica.
\end{abstract}

PALABRAS ClaVE: mercado de seguros; Cuba; compañías de seguros; siglo XIX.

Cómo citar este artículo / Citation: Cruz Pasos, Rosell, "El mercado de seguros en Cuba, siglo XIX", Revista de Indias, LXXIX/277 (Madrid, 2019): 863-895. https://doi.org/10.3989/ revindias.2019.025

\section{ANTECEDENTES, SIGLO XVIII}

Como el mercado de seguros es un espejo que refleja el desarrollo económico alcanzado en un momento dado, no puede estar ajeno a los acontecimientos que inciden en dicho avance, por eso, entre las circunstancias que propicia-

* Este artículo forma parte de un proyecto de libro sobre la historia del seguro en Cuba, actualmente en preparación.

1 rosell.veritates@nauta.cu, ORCID iD: https://orcid.org/0000-0001-5132-0440. 
ron su nacimiento y posterior impulso, están las ocurridas durante la segunda mitad del siglo XVIII que incentivaron el comercio en la isla. La comercialización de los bienes producidos estaba controlada por la Casa de Contratación de Sevilla desde su fundación en 1503 y por la ciudad de Cádiz a partir de 1717 cuando obtuvo el control monopólico del intercambio con La Habana.

Los vaivenes en el mercado azucarero consecuencia de crisis económicas y guerras imperiales, el tardío desarrollo de suficientes instituciones financieras y de seguros necesarias para lograr un real estímulo al comercio y la industria, así como el férreo monopolio comercial, condicionaron el lento progreso del seguro, que inicialmente actuaba por mero instinto y el avanzado arte de la imitación. Los antecedentes de mayor trascendencia para el surgimiento del seguro en la isla, comienzan el 13 de agosto de 1739, cuando el gobierno le adjudica al señor Aróstegui y a sus poderdantes el asiento general y exclusivo del tabaco, lo que llevó a la creación de la Compañía de Comercio de La Habana el 18 de diciembre de 1740 con un capital de novecientos mil pesos, en acciones de quinientos pesos cada una: mil de ellas para los socios peninsulares y las ochocientas restantes para los residentes en La Habana. La creación de almacenes para la operación de reexportación autorizada, constituyó una rentable posibilidad económica que permitió obtener importantes dividendos, lo que incentivó la utilización del seguro en la isla.

El pacto de familia que el rey español Carlos III firmó el 15 de agosto de 1761 con Luís XV rey de Francia, entre otras cosas, trajo como consecuencia la toma de La Habana por los ingleses. Alcanzando estos su viejo sueño de ocupar la mayor de las Antillas y asestar con ello un golpe definitivo al poder español en América. El gobierno británico que tomó el mando durante la invasión ${ }^{2}$, favoreció el comercio de la isla, el cual dejó de ser exclusivo con España, al dar autonomía para traficar con los buques de bandera inglesa ${ }^{3}$.

Al tomar posesión del gobierno en la isla, el conde de Ricla autorizó la compra de víveres en las colonias extranjeras mediante real cédula del 26 de octubre de 1763, contratando además la provisión de diez mil esclavos con los ingleses, lo que incrementó el potencial productivo y el capital asegurable. La ocupación inglesa representó un punto de viraje en el despertar socioeconómico de los cubanos, quienes no volverían a ser los mismos de antes, también propició cambios favorables en la legislación mercantil ${ }^{4}$.

2 Sir George Keppel, Conde de Albemarle, tomó el mando del 12 de agosto de 1762 al primero de enero de 1763 y Sir William Keppel — hermano de aquel- continuó hasta el 6 de junio de 1763 .

3 Guerra, 1989: 173-175.

4 Le Riverend, 1981: 103. 
En real cédula del 31 de mayo de 1763 se declaró que: «Los contratos de seguros, por vía de apuesta, serían siempre prohibidos y nulos como inicuos y opuestos a la humanidad», contrarios al espíritu de las leyes del título 39 del libro noveno de la recopilación de indias. Vuelto a formular por real cédula del 10 de noviembre de 1773 y reiterada su observancia, por real orden del 17 de diciembre de $1797^{5}$. Con estas órdenes, España daba un paso de avance en la industria del seguro al prohibir su funcionamiento basado en el azar, consecuentemente, obligaba a utilizar el cálculo actuarial en la ejecutoria del seguro, algo que no ocurrió inmediatamente; pero fue un paso decisivo en su posterior desarrollo.

El 12 de octubre de 1778 se aprobó el reglamento y aranceles reales para el comercio libre de España a Indias conocido como el decreto de libre comercio, el 18 de noviembre de 1797 se autorizó el tráfico de importación y exportación en cualquier bandera amiga, mientras durase la guerra contra Gran Bretaña ${ }^{6}$, estas medidas, junto a las ventajas que la posición geográfica le producían a $\mathrm{Cuba}^{7}$, incrementaron el intercambio comercial, favoreciendo al puerto de La Habana, al servir de estadía temporal para la mercadería destinada a otras plazas, demandando la creación de grandes depósitos y de aseguradoras que los respaldasen, dos negocios que se vieron favorecidos con ello.

El desarrollo alcanzado en la producción azucarera en la última década del siglo XVIII, la creación de la Sociedad Económica de La Habana - autorizada el 27 de abril de 1792 y fundada el 2 de enero de $1793^{8}$ - y del Consulado de Agricultura y Comercio, aprobado por real cédula del 4 de abril de 1794, el cual comenzó sus labores el 10 de abril de 1795', ambas constituidas para promover la agricultura, el comercio y la industria en Cuba, fueron antecedentes claves para el futuro de la vida económica del país.

Es difícil comprender el curso seguido por la historia de Cuba durante los dos últimos siglos, sin tener en cuenta el peso que ha tenido y tiene la industria azucarera en la vida económica del país. Esto no se limita al reconocimiento de su participación decisiva en la esfera de la economía o a su influencia en la formación de las ideas de los precursores del pensamiento económico cubano, como lo fueron Francisco de Arango y Parreño o el Conde de Pozos Dulces. El azúcar también

\footnotetext{
5 Gallardo, 1802: 185-186.

6 La Pezuela, 1878: 294.

7 Guerra, Pérez, Remos y Santovenia, 1952, tomo III: 237.

8 Guerra, 1989: 204.

9 Le Riverend, 1981: 263.
} 
resultó determinante en la introducción de las ideas científicas y en la aplicación de la tecnología en $\mathrm{Cuba}^{10}$.

Precisamente es en este contexto que surgen los mercados de seguros en las colonias americanas, favoreciendo a su vez la fundación de las primeras compañías nacionales: Compañía de Seguros Marítimos Nueva España (México, 1789); Compañía de Seguros Marítimos Santísima Virgen Nuestra Señora de Regla y el Señor San Cristóbal (Cuba, 1795) y Compañía de Seguros La Confianza (Argentina, 1796).

En realidad, el panorama aquí descrito fue mucho más complejo, ya que mientras esto ocurría sucedieron guerras, pactos, reformas y toda clase de componendas políticas en España, condicionando lo que acá ocurría. Solo se mencionan los eventos de mayor repercusión en la esfera mercantil-financiera que, eventualmente, influyeron en el funcionamiento del mercado de seguros en La Habana y, consecuentemente, en la fundación de aseguradoras en la isla, lo que constituye el máximo objetivo de nuestro estudio.

\section{Su entorno en La Habana}

El comienzo del siglo XIX fue nefasto para el seguro español, porque al año 1800 se había llegado con 101 compañías de seguros activas en la península y al año siguiente se había perdido el $75 \%$ de las mismas ${ }^{11}$. Comenzando la formación y/o consolidación de los mercados nacionales de seguro en varios países latinoamericanos como México, Argentina, Chile y Uruguay. El mercado de seguro cubano se materializó como reflejo del desenvolvimiento económico ocurrido a partir de las mismas fuerzas político-económicas que gestaron la nacionalidad cubana a finales del siglo XVIII, se puede afirmar que la fundación de la primera aseguradora cubana en 1795 fue otra confirmación de aquel hecho.

La aprobación del primer código de comercio ${ }^{12}$ en España el 30 de mayo de 1829 como norma para regular tanto la creación de las nuevas sociedades mercantiles, así como los ramos de seguros autorizados, significó un elemento de avance para la época, a pesar de que los clasificaba en dos ramos muy generales: marítimos y terrestres. Preveía la aprobación de la Ley de Enjui-

10 García Álvarez, 1999: vii.

11 Tortella, Caruana, García, Manzano y Pons, 2014: 58.

12 Redactado por Pedro Sainz y Andino, en vigor hasta el primero de enero de 1886, se inspiró en el Código Napoleónico de 1807. Véase Benito, 1895: 9. 
ciamiento sobre los negocios y causas del comercio, aprobada el 24 de julio de 1830, lo que agilizaba la creación y control de las nuevas sociedades. Decretaba instalar el tribunal de comercio, necesario, para el control del nuevo sistema financiero-mercantil, que resultaba ser más avanzado.

Esta norma provocó un primer impulso al seguro, una vez que entró en vigor en la isla, lo que ocurrió por real cédula del 1ro de febrero de $1832^{13}$, necesaria por la resistencia presentada por comerciantes y hacendados, ya que este avance institucional iba en detrimento de sus finanzas porque implicaba más control sobre ellos al tener que declarar sus negocios e informar sus ingresos, lo que a su vez, significaba más impuestos.

La pérdida definitiva de las colonias continentales como consecuencia de la derrota en la batalla de Ayacucho el 9 de diciembre de 1824 representó una disminución importante del comercio que España sostenía directamente con América, favoreciéndose con ello el intercambio de mercancías en el puerto de La Habana que pasó a ser el pivote del comercio español con América del norte y central.

Cuba y Puerto Rico, que siguieron sujetas a España hasta 1898, pasaron a ser piezas fundamentales del nuevo comercio americano. La política económica que aplicó España sobre sus colonias procuró hacer de las islas antillanas el centro de su comercio con América, para ello estableció depósitos de comercio que al menos hasta 1847 provocaron que los productos de América del Norte pasaran previamente por La Habana al tiempo que los de América del Sur hicieran escala en San Juan ${ }^{14}$.

Esta realidad impulsó la creación de grandes almacenes y la necesidad de incrementar el seguro, con el establecimiento de aseguradoras extranjeras se incentivó la fundación de las nacionales y su desarrollo técnico, entre otras cosas porque algunas se establecieron con fuerte participación del capital foráneo. Esto motivó que se promovieran medidas tendientes a su implementación, como la real orden del 28 de enero de 1848 que regulaba la creación de sociedades mercantiles, con su reglamento del 17 de febrero de ese propio año; así como del real decreto del 19 de octubre de 1853, promulgado por la real cédula del 29 de noviembre, que autorizaba al capitán general a aprobar la creación de sociedades mercantiles en La Habana, por lo que fue bien acogida por los hombres de negocios en la isla. Lo anterior, unido a otros factores coyunturales como el incremento de numerario, debido a buenas

13 Para 1833 se reporta en La Habana un incremento significativo de sociedades mercantiles de todo tipo, debido presumiblemente más al hecho de contar con un nuevo y obligatorio sistema de registro comercial que a un incremento real de estas. Véase García, 1990: 70.

14 Yáñez, 2006: 692. 
zafras azucareras y al incremento del precio del azúcar ${ }^{15}$ y a una disposición favorable de las fuerzas gobernantes en la metrópoli, que deseaban un acrecentamiento de la industria y el comercio en la isla, propiciaron la creación de diez nuevas compañías de seguros, con los más disímiles propósitos, durante el boom fundacional de 1855-1857, en la primera tabla se relacionan las sociedades mercantiles más importantes creadas, a las que Ramón de La Sagra llamó: «Instituciones auxiliares del comercio y cooperadoras al desarrollo material del país» ${ }^{16}$.

Tabla 1. Sociedades COMERCIALES CREADAS EN EL TRIENio 55-57

\begin{tabular}{|l|l|c|}
\hline Aprobadas & \multicolumn{1}{|c|}{ Denominación } & $\begin{array}{c}\text { Cap. } \\
\text { suscrito }\end{array}$ \\
\hline $05 / 01 / 1855$ & Compañía de Seguros Mutuos La Previsora. & n. d. \\
\hline $26 / 01 / 1855$ & Compañía de Seguros Mutuos La Hereditaria. & n. d. \\
\hline $20 / 02 / 1855$ & Compañía de Seguros Mutuos El IRIS. & n. d. \\
\hline $20 / 11 / 1855$ & Compañía General Cubana de Seguros Mutuos La Protectora. & n. d. \\
\hline $00 / 00 / 1855$ & Compañía Almacenes de Depósitos de Hacendados. & 622000 \\
\hline $19 / 02 / 1856$ & Sociedad del Crédito Industrial. & 600000 \\
\hline $09 / 04 / 1856$ & Banco Español de la Habana. & 750000 \\
\hline $04 / 09 / 1856$ & Compañía de Seguros Mutuos La Propietaria. & n. d. \\
\hline $11 / 10 / 1856$ & Compañía de Seguros Mutuos La Indemnizadora. & n. d. \\
\hline $00 / 00 / 1856$ & Compañía Ferrocarril y Almacenes Depósitos de Cuba. (Stgo). & 1000000 \\
\hline $15 / 03 / 1857$ & Banco Agrícola. & 500000 \\
\hline $11 / 03 / 1857$ & Compañía Almacenes Santa Catalina de Sena. & 184000 \\
\hline $05 / 04 / 1857$ & Sociedad de Crédito Mercantil e Industrial de Cárdenas. & 500000 \\
\hline $05 / 05 / 1857$ & Banco de Cuba. (Santiago). & 600000 \\
\hline $09 / 06 / 1857$ & Sociedad Crédito Agrícola Mercantil Cubano. & 1000000 \\
\hline $13 / 06 / 1857$ & Banco de Garantía y Crédito. & 562000 \\
\hline $16 / 06 / 1857$ & Compañía Internacional de Banco y Seguro, S.A. & 600000 \\
\hline $08 / 07 / 1857$ & Sociedad General del Crédito Territorial Cubano. & 900000 \\
\hline $13 / 07 / 1857$ & Banco Industrial Pecuario. & 150000 \\
\hline
\end{tabular}
.......

15 Durante el trienio 1855-1857, en el mercado de Londres, el precio del azúcar subió a 5,63; 6,57 y 7,98 ф/lb, respectivamente. Véase. Roldán, 2004: 37.

16 La Sagra, 1862: 244. 
$\ldots / \ldots$

\begin{tabular}{|l|l|c|}
\hline Aprobadas & \multicolumn{1}{|c|}{ Denominación } & $\begin{array}{c}\text { Cap. } \\
\text { suscrito }\end{array}$ \\
\hline $21 / 07 / 1857$ & Banco de Pinar del Río. & 500000 \\
\hline $17 / 10 / 1857$ & Compañía Crédito y Seguros La Alianza S.A. & 2800000 \\
\hline $00 / 00 / 1857$ & Banco de Comercio. & 2000000 \\
\hline $00 / 00 / 1857$ & Banco Pedroso y Compañía. & 2400000 \\
\hline $00 / 00 / 1857$ & Caja de San José. & 1500000 \\
\hline $00 / 00 / 1857$ & Caja Central de Comercio. & 500000 \\
\hline $00 / 00 / 1857$ & Caja Comercial. & 900000 \\
\hline $00 / 00 / 1857$ & Caja del Crédito Agrícola de Cárdenas. & 300000 \\
\hline $00 / 00 / 1857$ & Caja de Préstamo. & 144000 \\
\hline $00 / 00 / 1857$ & Compañía Almacenes de Marimelena. & 500000 \\
\hline $00 / 00 / 1857$ & Compañía de Seguros La Positiva y Banco Gral. de Fomento. & 1500000 \\
\hline $00 / 00 / 1857$ & Compañía de Seguros Marítimos de Matanzas. & n. d. \\
\hline $00 / 00 / 1857$ & Sociedad Gral. de Crédito Mobiliario y Fomento Cubano. & 4000000 \\
\hline
\end{tabular}

Fuente: elaborada por el autor, basado en Erénchun, 1857-1861, La Sagra, 1862 y Tablada y Castelló, 2007.

Las sociedades financieras creadas estaban íntimamente relacionadas con las de seguro, primero, en la propia concepción del programa implementado, donde las de crédito otorgarían el financiamiento y las aseguradoras lo afianzarían; en segundo lugar, estaban las instituciones que realizaban las dos funciones, banco-seguro como fueron los casos de La Internacional, La Positiva y La Alianza. Otras eran agentes de seguros y vendían pólizas relacionadas al giro específico de su actividad crediticia: agrario, industrial, mobiliario, mercantil, etc. las que no realizaban estas actividades de mediación, también acrecentaban el seguro al exigirle a sus clientes pólizas que protegiesen aquello sobre lo cual se realizaban los préstamos.

Desde un inicio los grandes almacenes de depósitos creados, estuvieron vinculados, por una parte, a las sociedades crediticias al ser autorizados a realizar limitadas operaciones bancarias. Los ejemplos de mayor relevancia fueron: los Almacenes de Regla ${ }^{17}$ (1844) autorizado a operar una caja que en

17 El primer edificio de los almacenes de regla —ocho naves - se construyó en 1844 y comenzó a operar en la zafra de 1845, luego se construyeron otros dos. En 1850 se formó una compañía de almacenes con un nuevo edificio - 10 naves - que en 1854 se fusiona con la 
1857 se convirtió en el Banco de Comercio; y el Almacén de San José (1853) que se transformó en la Cía. de Almacenes y Banco de San José también en 185718. Los Almacenes de Depósitos para Hacendados (1855), fueron autorizados en 1857 para crear su propio banco; pero al no lograr suscribir el capital necesario por efectos de la crisis, no llegó a establecerse. También se vinculaban a las aseguradoras al servirles de agentes y/o al ser sus más importantes clientes.

Otra forma común de relacionarse entre sí estas sociedades comerciales era a través de la inversión directa, como ejemplo de ello puede mencionarse el caso de la Sociedad General del Crédito Territorial Cubano, dedicada al crédito agrícola, quien tenía acciones en el Banco Agrícola, en la Compañía de Crédito y Seguros La Alianza, en la Compañía Almacenes de Hacendados y en otras varias de ferrocarriles. Para un mejor entendimiento de las relaciones entre bancos, almacenes y aseguradoras, se recomienda ver el libro $L a$ historia de la banca en Cuba, tomo I, de los autores Tablada y Castelló.

Lamentablemente, el espíritu fundacional de aquel trienio se salió de control en 1857 ante la solicitud masiva de nuevas sociedades mercantiles, el error consistió en la aprobación de 136 de las 263 solicitudes presentadas sin que existiese un adecuado respaldo financiero. Sobre la crisis monetaria de 1857 en La Habana se ha especulado bastante, es cierto que afectó el comercio y sobre todo la credibilidad del sistema bancario y sus instrumentos de pago. Pero también es cierto que el boom fundacional de aquel año se habría detenido de todas formas porque no existía la cantidad de dinero necesario para suscribir el capital de aquellas sociedades tan imprudentemente autorizadas, por lo que las entidades disueltas, fusionadas o liquidadas habrían tenido igual suerte sin la estrechez de dinero que coyunturalmente se manifestó; aunque no se puede decir lo mismo de las quebradas debido a las operaciones bursátiles realizadas con aquellas acciones sobrevaloradas, que habían sido vendidas y revendidas repetidamente, responsables directas de la especulación acontecida.

La aprobación de La Alianza, después de la suspensión decretada, se justifica porque incluía entre sus funciones la de: «Tomar a su cargo la liquida-

primera, dando lugar a la Compañía de Almacenes de Regla, con un capital (en conjunto) de 1,5 millones de pesos. El 23 de julio de 1863 un gran incendio causó daños valorados en 1 618163 pesos, antes del año se habían recuperado del siniestro — estaban asegurados con una compañía inglesa-, en 1864 repartieron utilidades del 14\% y sus acciones se cotizaban al $121 \%$. Posteriormente al incendio construyeron el quinto edificio con 13 naves. Cantero, 1857: 18-19. La Pezuela, 1863: 315-317.

18 La Pezuela, 1863: 317. Le Riverend, 1981: 415. 
ción y fusión de toda clase de sociedades mercantiles conforme a las leyes» ${ }^{19}$. También fue autorizada al corretaje de seguros, a la refacción hipotecaria en la industria azucarera y a la actividad mayorista, etc. Lo que contribuía a la solución de la situación creada con las sociedades autorizadas y en proceso de formalización durante aquel año, resultando un aporte a la terminación de la crisis, una vez percatados que parte de la responsabilidad estuvo dada por la autorización masiva de sociedades sin notoria utilidad pública y escasos recursos financieros, dos importantes preceptos que debían cumplirse; pero que fueron omitidos, ejemplos de ello fueron las 18 de Galiano ${ }^{20}$ y las 19 de La Sagra ${ }^{21}$.

El real decreto del 5 de diciembre de 1860 creó la inspección general para la isla de Cuba de toda clase de sociedades mercantiles por acciones, de seguros mutuos y los ferrocarriles ${ }^{22}$. Este órgano de control es el antecesor más antiguo, en Cuba, de la superintendencia de seguros actual; aunque, como ya se dijo, no controlaba solamente a este sector de la economía. Estaba bajo las órdenes directas del capitán general, como inspector general fue nombrado a Cipriano del Mazo y como oficial a José Romero, los que debían velar para que las organizaciones comerciales cumplieran con la nueva legislación.

Debido al número creciente de compañías de seguro de incendios, principalmente extranjeras, el 13 de abril de 1875 fue creada la Asociación Cubana de Compañías de Seguros Contra ${ }^{23}$ Incendios, la cual agrupaba a todas las compañías nacionales y extranjeras del ramo.

Sus fines son principalmente de regulación de las tarifas de primas para dicho ramo. Se mantienen neutrales en todas las controversias que surjan entre compañías nacionales y las compañías extranjeras, en relación con las aspiraciones de las

19 La Pezuela, 1863: 337. Debido a esta función especial, La Alianza recibió en sus arcas los capitales de las entidades a liquidar: el Banco de Pinar del Río; la Caja Central de Comercio; la Caja de Crédito Agrícola de Cárdenas; La positiva, compañía de banco y seguros; el Banco Agrícola y La internacional; compañía de banco y seguros. Seguramente por desconocimiento de los autores de la época y después por repetición, se ha dicho que todas esas entidades se fusionaron con La Alianza, lo que, a la luz de los nuevos conocimientos, es un error, pues ella actuaba como liquidadora oficialmente instituida.

20 Galiano, 1859: 165.

21 La Sagra, 1862: 247.

22 Tablada y Castelló, 2007: 149.

23 Era habitual, tanto en Cuba como en España, nombrar a las compañías de seguros de incendios: «Contra incendios», también se utilizaba en la bibliografía y publicidad de la época. 
primeras en favor de una legislación de seguros parecida a las que rigen en todos los países avanzados ${ }^{24}$.

Esta entidad cubana fue la primera institución agrupadora del seguro en Latinoamérica, le siguieron el Comité Argentino de Aseguradoras (1894) y la Asociación Mexicana de Agentes de Seguros (1897). En 1909 la asociación cubana se incorporó al Fire Office Committee (FOC) Foreign de Londres y en 1922 a la United States Fire Conference of New York.

El FOC fue establecido oficialmente en 1868; pero desde 1790 las compañías Sun Fire Offices, Phoenix Fire Offices y Royal Exchange Assurance, se habían unido con el propósito de unificar tarifas y controlar el mercado, luego se incorporaron las demás, mientras que su Comité Extranjero trabajaba por unificar las pólizas y disciplinar el mercado — seguro de incendio- del país allá donde fueren sus compañías miembros, lo cual acrecentaba el mercado.

Existieron en nuestro mercado mediadores que representaron diversas compañías de seguros extranjeras. El Anuario de 1879 recoge la existencia de once de estos agentes en La Habana: A. G. Dickinson, Berandes y Cía., Carlos Ladendorff, E. Arnad, F. C. Schmidt y Cía., Falk Robisen y Cía., Felipe Núñez, Hayley y Cía., J. F. Millinton, Ricardo P. Kohly, Will y Hermanos ${ }^{25}$. Lo que corrobora la existencia de un mercado de seguros en Cuba según todas las pautas establecidas, es decir, un lugar donde se integraban oferta y demanda de seguros, compuesto por aseguradores, asegurados, intermediarios y un ente regulador. Con el objetivo de satisfacer las necesidades y/o deseos de protección financiera ante riesgos potencialmente dañosos y legalmente establecidos como asegurables.

El 22 de agosto de 1885 se aprobó el segundo Código de Comercio español que entró en vigor el primero de enero de 1886, en Cuba fue instaurado el primero de mayo del mismo año. Como norma más avanzada que la anterior, incluía dos nuevos ramos: los seguros de incendios y sobre la vida, que ya se comercializaban dentro del esquema amplio que establecía el anterior código. Instituyendo cambios en el mecanismo de creación de las sociedades mercantiles, dedicando su título VIII a los contratos de seguro (arts. 380-438), lo que constituyó un acontecimiento relevante para esta industria. En este código los seguros fueron clasificados en cuatro ramos: incendio, sobre la vida, transporte terrestre y transporte marítimo.

El primero de diciembre de 1893 se dictó la que está considerada como la primera norma jurídica de seguros para nuestro país, la Instrucción para la

\footnotetext{
24 Ortega, 1943: 30.

25 Bailly, 1879: 1539.
} 
Administración, Investigación y Cobranza de los Impuestos a las Compañías de Seguros. Sus cinco capítulos establecían:

1. Las bases del impuesto que, en sustitución de la contribución industrial, con arreglo al artículo 32 de la ley de presupuestos de la península, del 5 de agosto de 1893 hecha extensiva a Cuba y Puerto Rico por real orden del 8 de agosto de 1893, imponía un impuesto del 2\% sobre las primas que anualmente eran percibidas por las aseguradoras. Según la primera ley de control estatal para las personas dedicadas a las actividades aseguradoras, del 16 de diciembre de 1892.

2. La obligación de efectuar balances contables y de tributar información a la administración del gobierno.

3. La obligación de crear reservas técnicas.

4. La obligación de depositar, en concepto de garantía, la cantidad de doscientos mil pesos a la orden de la tesorería en un banco de $\mathrm{La}$ Habana, ya sea en efectivo o en documentos negociables por igual valor, ejecutables en España, Cuba o Puerto Rico.

5. La facultad de investigación a la inspección administrativa del gobierno, de las causales de defraudación y penalidad.

Esto constituyó un momento importante para el seguro en Cuba, si bien es cierto que algunas de estas normas no pasaban de ser puramente administrativas, útiles para las arcas de la capitanía, lo que plantean los incisos tercero y cuarto era de mayor alcance para el desarrollo del seguro. La obligación de crear reservas técnicas y crear garantías financieras a disposición de la tesorería del gobierno, mejoraban tanto la capacidad de permanencia como de actuación de las aseguradoras en el mercado. Las que, no obstante, siguieron siendo débiles, porque se fundaban con escasos recursos financieros, en un mercado liderado por las aseguradoras extranjeras y sin el respaldo técnico necesario.

\section{COMPAÑÍAS DE SEGUROS ESPAÑOLAS}

Las aseguradoras españolas fueron las primeras en hacerse presentes y las hubo de diversos tipos: tontineras, mutualidades, sociedades anónimas, Lloyd, etc. - por razones prácticas hemos preferido mostrar separadamente las fundadas en la península de las creadas en La Habana-. Durante los siglos XVI-XVIII el comercio de la isla con la metrópolis, era asegurado desde Sevilla primero y desde Cádiz después, según estas ciudades tuvieron el privilegio de controlar tal comercio. 
El aseguramiento se hacía bajo los mecanismos usuales de cada época, con aseguradores individuales primero, después con las compañías que se iban fundando, según hubo un mayor desarrollo de esta industria en España. A partir de las negociaciones con el Reino Unido para recuperar La Habana en 1763, esta plaza se libera de la imposición comercial preestablecida, lo que implicó de manera indirecta, un progreso para el comercio de la isla y consecuentemente, también incidió en el surgimiento del seguro en el país.

En el siglo XIX el seguro español marchaba a la zaga del europeo; pero daba pasos en su progreso, así en 1841 se elabora la primer tabla española de mortalidad, basada en la experiencia de siete países de aquel continente ${ }^{26}$. En la década de 1860 fueron editados varios libros sobre el seguro: Manual de seguros marítimos, José Mas Clotet (Madrid, 1861); Instrucciones prácticas para los agentes de seguros contra incendio y sobre la vida y para los asegurados, José Palau y Rivalaigua (Barcelona,1863); Manual de Comercio y Navegación, José Mas Clotet (Madrid, 1864); Estudios sobre seguros, Eugenio Reboul (Madrid, 1865); La Póliza de seguro contra incendios (Biblioteca de seguros) Josep Rubau Donadeu (Madrid, 1869) ${ }^{27}$. Lo que sin dudas permitió mejorar el respaldo teórico de esta industria.

En el estudio se encontró evidencia de al menos catorce aseguradoras españolas presentes en Cuba en los siglos XVIII y XIX ${ }^{28}$ de diferentes tipos:

1. María Santísima de los Dolores. Seguros marítimos. (1783-1794).

2. La Purísima Concepción de María Santísima. Seguros Marítimos. (1789-1794).

3. Compañía de Seguros Terrestres y Marítimos de Madrid. (1786-1797).

4. La Tutelar, Sociedad de Seguros Mutuos de vida. (1850-1855).

5. El Porvenir de la Familia, Sociedad de Seguros de vida. (1851-1856).

6. La Unión, Compañía General de Seguros de incendio. (1856-1857).

7. La Naviera Catalana, Compañía de Seguros Marítimos. (1857-1857).

8. La Masnouense Compañía de Seguros Marítimos. (1857-1857).

9. Montepío Universal, Cía. General Española de Seguro Mutuos sobre la Vida. (1856-1860).

26 Tortella, Caruana, García, Manzano y Pons, 2014: 89.

27 Torres, 1883: 145.

28 Listado elaborado por el autor, basado en Gallardo, 1796-1808, Erénchun, 1857-1861, Anuario estadístico..., 1859, Almanaque..., 1860, Bailly, 1879, Guerra, Pérez, Remos y Santovenia, 1952, Pons, 2010, Tortella, Caruana, García, Manzano y Pons, 2014 y Cruz, 2016. Entre paréntesis se indica primero el año de fundación de la compañía y a continuación el de su establecimiento en Cuba, fecha más antigua confirmada. 
10. Caja Universal de Capitales, Compañía de Seguros Mutuos sobre la Vida. (1859-1861).

11. Compañía General Española de Seguros. (1850-1879).

12. La Aseguradora, Compañía de Seguros. (1856-1879).

13. La Unión y el Fénix Español, Compañía de Seguros Reunidos, S.A. (1879-1879).

14. Lloyd Andaluz, sociedad de seguros marítimos. (1864-1879).

Las sociedades tontineras, eran una modalidad del seguro de vida sin fundamento científico, constituían una forma de ahorro sobre la base de la mutualidad con diferentes formas de organizarse. Populares en la España del siglo XVIII, en 1746 se construyó una tabla de mortalidad basada en esta experiencia, que en 1867 fue perfeccionada, siendo utilizada en Francia para realizar los cálculos en los seguros de vida.

En el siglo XIX, pasaron a ser una reunión de personas que aportaban cuotas mensuales, las que se invertían en activos de diversos tipos durante un período de tiempo fijo. Al expirar el plazo, el capital más los intereses acumulados se distribuían entre los sobrevivientes, a diferencia de lo que ocurría en el sistema original donde el estado no devolvía el capital tomado, ya que solo pagaba los intereses, por lo tanto, dejaron de ser sociedades de rentas vitalicias para convertirse en sociedades de capitalización ${ }^{29}$.

El Lloyd's of London surgió en 1688 como una asociación de aseguradores individuales, integrados en grupos independientes entre sí, denominados syndicates, alcanzando tal éxito a través de los años, que en todas partes se trató de imitarlos. Porque su estructura facilitaba los trámites, permitía asumir mayores riesgos al tener un mayor respaldo económico y no estar tan regulados por el gobierno. Es la institución aseguradora más antigua del mundo en operaciones y una de las más poderosas.

Eran reuniones de aseguradores formados por navieros, comerciantes y otros particulares que, cada uno por sí mismo, sin mancomunidad ni solidaridad alguna, garantizaban la póliza, sin existencia jurídica definida ${ }^{30}$.

Donde el socio de mayor experiencia estaba encargado de abrir cada contrato, los demás se limitaban a aceptar una porción del riesgo, aplicando la tarifa determinada por el primero. Los hubo en todas partes, además del inglés, fueron creados el Lloyd francés, el español, el alemán, el suizo, el americano,

29 Tortella, Caruana, García, Manzano y Pons, 2014: 93.

30 Ibidem: 98. 
etc. Para el caso particular de España existieron el Lloyd vascongado (1848), el gaditano (1850), el malagueño (1851), el barcelonés (1855), el catalán (1857), el bilbaíno (1861), el andaluz (1864) y el habanero (anterior a 1865) ${ }^{31}$. Era frecuente que se le asignase el nombre de Lloyd a diferentes tipos de sociedades mercantiles, haciéndose difícil en ocasiones, su diferenciación.

Las compañías radicadas en La Coruña, La Purísima Concepción y María Santísima de los Dolores, son las primeras aseguradoras españolas de las que tenemos noticias en el mercado de La Habana, en 1794. El director de la primera, Miguel de Santisteban, que la había fundado con quinientos mil pesos divididos en doscientas cincuenta acciones, tenía por apoderado en $\mathrm{La}$ Habana a Felipe Fernández de Silva, radicado en la calle de Mercaderes, $n$. ${ }^{\circ}$ 147. Mientras que el comisario de guerra Gerónimo Hijosa, director de la segunda, había fundado la suya con seiscientos mil pesos y tenía a Mariano Carbó en igual cargo en la calle Lamparilla n. ${ }^{\circ}$ 87. Aseguraban el riesgo de mar y/o riesgo de enemigos, juntos o por separado, para viajes Habana-España y Habana-puertos de América (española) y en sentido contrario. Cobraban las tarifas habituales de las demás compañías radicadas en Cádiz. Ambas compañías aparecen hasta 1808 en este mercado, incrementándose en cuatro años, lo reportado por otros autores para estas ${ }^{32}$.

Era común cobrar tarifas diferentes en el viaje de ida con respecto al de regreso, algunas compañías incrementaban las primas si ocurría el siniestro, como la aseguradora Nueva España, radicada en Veracruz, la cual cobraba 2\% en el viaje de ida a España y 8\% en el de regreso; si ocurría el siniestro, entonces las incrementaban —automáticamente - a 20 y $16 \%$ respectivamente ${ }^{33}$, actuando en la práctica como un deducible, porque se descontaba de la indemnización la parte de la prima no satisfecha.

La Compañía de Seguros Terrestres y Marítimos de Madrid, fue la primera privilegiada con responsabilidad limitada de aquella ciudad ${ }^{34}$, Joaquín de Quintana fue su representante en La Habana en el año 179735. Las aseguradoras Masnouense y Naviera Catalana ofertaban seguro marítimo, fueron re-

31 Desconocemos la fecha de su fundación; pero en 1865 la sociedad norteamericana Sun Mutual Insurance Co., fundada en 1841, reportó a la superintendencia de seguros de aquel país, tener oro depositado en el Lloyd Habanero, seguramente a manera de inversión de capital, lo que prueba su existencia aquel año. Barnes, 1866: 425.

32 Gallardo, 1796: 418-419. Calendario, 1795: 69-72.

33 Ibidem: 423,425.

34 Tortella, Caruana, García, Manzano y Pons, 2014: 55-56.

35 Guerra, Pérez, Remos y Santovenia, 1952, tomo III: 219. 
presentadas en La Habana por Larrua, Canet y Cía. y Cavela y Gaudeny, respectivamente ${ }^{36}$.

En 1856 es creada en Madrid, La Unión, compañía general de seguros, su director general Ramón López de Tejada bajo la presidencia de Francisco Santa Cruz, ofertaba seguros marítimos, de vida e incendio. Ocupándose además de la gerencia de las sociedades mutuas, La Unión Española y El Porvenir de la Familia ${ }^{37}$, hasta 1879 en que la primera de ellas se funde con El Fénix Español (1864) para formar La Unión y el Fénix Español. Estas aseguradoras estaban representadas en La Habana por un agente radicado en la calle Aguiar, n. ${ }^{\circ} 93$.

\section{COMPAÑÍAS DE SEGUROS CUBANAS}

El 24 de enero del año 1795 fue creada la primera aseguradora en la isla, la compañía de seguros marítimos Santísima Virgen Nuestra Señora de Regla y el Señor San Cristóbal. Las sociedades mercantiles, al crearse, podían adoptar diferentes fechas fundacionales, todas igualmente válidas (lo que justifica, en parte, la discrepancia entre autores, al disponer de diferentes documentos probatorios), entre las más significativas se pueden mencionar: solicitud de autorización, aprobación por el gobierno central, ratificación en La Habana, publicación en la gaceta, inscripción en el registro de sociedades mercantiles, comienzo de explotación y modificación o refundación. Hemos preferido, siempre que ha sido conocida, utilizar la fecha de su aprobación en la isla.

La refundación de compañías era una práctica comúnmente aceptada para evitar engorrosos y dilatados trámites burocráticos, como fueron los casos de dos importantes aseguradoras; La Compañía de Seguros Marítimos de La Habana (1838), refundada de su predecesora Especulación (1833); y El Iris (1855), que lo fue de La Mutualidad (1852). Cuando se refundaba una compañía, los nuevos dueños no alcanzaban la condición de fundadores, lo que significaba que perdían los derechos fundacionales que eran automáticamente adjudicados al gobierno.

La cláusula restrictiva que insertaba el gobierno en la aprobación de la compañía, generaba las «Póliza primer día» que eran las emitidas el día que se daba cumplimiento a tal exigencia, cuando entraba en operaciones, porque de no lograrlo, la compañía era disuelta y no llegaba a constituirse formalmente.

\footnotetext{
36 Vigil, 2010: 65.

37 Almanaque..., 1860: 200-201.
} 
En la búsqueda realizada se encontró evidencia de al menos veintidós aseguradoras fundadas en La Habana durante los siglos XVIII y XIX ${ }^{38}$ :

1. Santísima Virgen Nuestra Señora de Regla y el Señor San Cristóbal. Seguros Marítimos. Fundada el 24 de enero de 1795.

2. Compañía de Seguros Marítimos. Fundada en el año 1802.

3. Especulación, Compañía de Seguros Marítimos. Fundada el año 1833.

4. La Providencia, Compañía de Seguros Mutuos sobre la Vida y Valores de los Esclavos. Fundada en el año 1833.

5. Compañía de Seguros Marítimos de La Habana. Fundad el 8 de marzo de 1838.

6. La Mutualidad, Compañía de Seguros Contra Incendios. Fundada en el año 1852.

7. La Previsora, Compañía de Seguros Mutuos Sobre la Vida de los Ganados. Fundada el 5 de enero de 1855.

8. La Hereditaria, Compañía de Seguros Mutuos Sobre la Vida. Fundada el 26 de enero de 1855.

9. El Iris, Compañía de Seguro Mutuos Contra Incendios. Fundada el 20 de febrero de 1855 .

10. La Protectora, Compañía General Cubana de Seguros Mutuos Sobre la Vida de los Esclavos. Fundada el 20 de noviembre de 1855.

11. La Propietaria, Compañía de Seguros Mutuos Sobre Alquileres. Fundada el 4 de septiembre de 1856.

12. La Indemnizadora, Compañía de Seguros Mutuos Contra Quiebras. Fundada el 11 de octubre de 1856.

13. Compañía Internacional, Banco y Seguro, S.A. Fundada el 16 de junio de 1857.

14. La Alianza, Compañía de Crédito y Seguros, S.A. Fundada el 17 de octubre de 1857.

15. Compañía de Seguros Marítimos de Matanzas. Fundada en el año 1857.

16. La Positiva y Banco General de Fomento. Fundada en el año 1857.

17. Compañía de Seguro de Quintas. Fundada el 20 de agosto de 1859.

18. Lloyd Habanero, Sociedad de Seguros Marítimos. Fundada antes del año 1865.

38 Listado elaborado por el autor, basado en Erénchun, 1857-1861, La Sagra, 1862, Bai1ly, 1879, Guerra, Pérez, Remos y Santovenia, 1952, Tablada y Castelló, 2007, Vigil, 2010 y Cruz, 2016. Se excluyeron dos por falta de confirmación. 
19. La Humanitaria, Sociedad de Seguros de vida. Fundada el 20 de agosto de 1888 .

20. El Fénix, Compañía de Seguros de Vida. Fundada en el año 1891.

21. El Círculo Cosmopolita, Compañía de Seguros. Fundada en el año 1895.

22. La Unión Antillana, S.A. Compañía General de Seguros y Fianzas. Fundad el 27 de septiembre de 1899.

\section{Seguros maritimos}

El comercio marítimo de la isla incentivó el nacimiento del seguro cubano, creándose bajo la invocación de la Santísima Virgen Nuestra Señora de Regla y el Señor San Cristóbal, la unánimemente aceptada como la primera compañía de seguros marítimos bajo la dirección de Pedro Diago. Fundada con un capital de ochocientos mil pesos, dividido en ciento sesenta acciones de cinco mil pesos cada una. Cobraba una prima del $2 \%$ para viajes a España y del 1,5\% para los puertos de las colonias españolas de América, estando autorizada a realizar algunas operaciones bancarias. Se justificó con la necesidad de garantizar una pronta indemnización (en La Habana) a los comerciantes del seno mexicano, que en caso de pérdida estaban obligados a ir hasta $\mathrm{La}$ Coruña para recibir su indemnización, lo que interrumpía la cadena de negocios de cada viaje al tener que solicitar empréstitos para reponer la pérdida y continuar con su actividad comercial. Alcanzó trece años de explotación confirmados.

En 1802 fue fundada la segunda compañía de seguros marítimos — se desconoce su nombre oficial - con un capital de dos millones trescientos mil pesos, bajo la dirección de Felipe Fernández de Silva y Miguel de Arambarri, como interventor-consultor fue nombrado Joseph Antonio de Arregui 39 . Esta compañía continuaba operando en 1808 , al igual que la anterior ${ }^{40}$.

Otra compañía de seguros marítimos fue fundada en 1833, a la que pusieron por nombre Especulación, por un período de seis años y un capital de quinientos mil pesos, en acciones de cinco mil pesos cada una, por el regidor del ayuntamiento constitucional de La Habana, José Ramón Martelo y Otero ${ }^{41}$. Esta compañía fue modificada en 1835 y el 8 de marzo de 1838 resultó refundada por José Miguel Urzinqui, siendo autorizada por otros seis años más,

\footnotetext{
39 Gallardo, 1803: 422.

40 Ibidem, 1808: 479.

41 García, 1990: 73.
} 
ocasión que aprovechan para cambiarle el nombre, a partir de aquel momento se llamaría oficialmente Compañía de Seguros Marítimos de La Habana ${ }^{42}$, nombre popular con el cual era conocida.

Las aseguradoras marítimas eran autorizadas a realizar limitadas operaciones bancarias, motivado por la escasez de instituciones financieras en La Habana. En su balance económico del año 1849 reportó ganancias por su actividad bancaria de 123977 pesos, mientras que por su cartera de seguros solo consiguió $16526^{43}$. El 3 de diciembre de 1870 por voluntad de sus accionistas se extinguió la sociedad, convirtiéndose en el Banco Mercantil de La Habana, S.A. ${ }^{44}$

Posteriormente se fundaron otras compañías que comercializaron el ramo de seguros marítimo, como la Internacional y la Positiva, el ejemplo más fecundo de este período fue el Lloyd Habanero, quien gozó de prestigio y respeto en La Habana del último tercio de siglo, por su permanencia en el mercado y la transparencia en sus operaciones. Se trató de una sociedad mercantil que pudo haber comenzado como una reunión de aseguradores individuales, en 1879 funcionaban junto a él en La Habana: el Lloyd Americano, el Lloyd Suizo y el Lloyd Andaluz ${ }^{45}$.

\section{Seguros de esclavos}

Del seguro de esclavos en general se ha escrito poco y como norma se evita el tema por lo escabroso del mismo. En la península no hubo compañías especializadas en esta línea de seguro, al parecer fueron inventadas en esta isla, en los Estados Unidos se han encontrado contratos de compañías de seguros de vida que aseguraron a esclavistas de aquel país, sobre la muerte de sus esclavos; pero tampoco hubo compañías especializadas. En marzo del año dos mil, Aetna Life Insurance, compañía norteamericana fundada en 1853, fue criticada por participar del seguro de esclavos en el siglo XIX, por lo que tuvo que disculparse expresando su «profunda pena» por haber participado en $\tan$ «deplorable práctica» ${ }^{46}$.

42 Erénchun, 1856, tomo IV: 2427-2432. Guerra, Pérez, Remos y Santovenia, 1952, tomo III: 256. Mascarós, 2004: 20. Tablada y Castelló, 2007: 188.

43 Araujo, 1850: 17.

44 Tablada y Castelló, 2007: 190.

45 Bailly, 1879: 1539.

46 Véase Slaver \& Insurance Examining slave insurance in world 150 years removed, by Michael Sean Quinn, May 15, 2000, en http://www.insurancejournal.com/magazines/insurance-journal-west-2000-05-15/ 
Fue la colonización del continente americano por las metrópolis europeas lo que incrementó la esclavitud hasta niveles nunca antes vistos, creándose desde las costas de África la trata negrera, a través del llamado mercado triangular. En Cuba la esclavitud fue un negocio lucrativo que a su vez sustentó el desarrollo de la industria azucarera de la isla, justificado con la necesidad de mano de obra, algo que, a los ojos y bajo los estándares vigentes en aquella sociedad era aceptado; aunque desde un comienzo hubo voces que se alzaron contra aquella inhumana práctica.

Los tratadistas portugueses fueron los pioneros en facilitar a los hacendados la mano de obra esclava con créditos pagaderos con los frutos del país. La contrata de negros concertada en 1595 con el portugués Pedro Gómez garantizó la entrada de cerca de mil esclavos a La Habana ${ }^{47}$.

El alto costo de los cientos de miles de esclavos introducidos como mano de obra, favoreció el surgimiento de aseguradoras especializadas, creadas con el objetivo específico de proteger financieramente la inversión que hacían los esclavistas. Estas compañías trataban de ser vistas como aseguradoras de vida, por eso se inscribían como compañías de seguros sobre la vida de los esclavos, en realidad no vendían seguros de vida. No lo eran, porque no cumplían los principales requerimientos de tales instituciones: los esclavos eran objeto del seguro y no sujetos que pudiesen mediar o influir en la concertación del mismo; se les aplicaba un valor asegurable definido por la aseguradora según sus propias tablas clasificadoras, teniendo en cuenta el valor en plaza; y porque una vez hecha la indemnización al asegurado, la aseguradora podía subrogarse en grado y lugar de aquel. Se aplicaba el concepto indemnizatorio, propio de los seguros de daños.

En 1833 se fundó La Providencia, Compañía de Seguros Mutuos sobre la Vida y Valores de los Esclavos, autorizada por un período de cincuenta años ${ }^{48}$. La misma aseguraba los esclavos de uno a sesenta y cinco años empleados en las ciudades y en la agricultura, indemnizaba los que fallecieren o sufrieran algún menoscabo superior al $25 \%$ por causas involuntarias, exceptuando el suicidio y el resultado de la sevicia. El contrato era por cinco años y la compañía tenía su propio médico.

El 6 de julio de 1854 Miguel de Embil, eleva a las autoridades, una solicitud con los informes favorables de la junta de fomento, el alcalde mayor, el tribunal mercantil y el real acuerdo, para refundarla. El día 23 de agosto de 1855 el capitán general de la isla ratifica la aprobación del mes anterior hecha

\footnotetext{
47 García, 2004: 28.

48 Tablada y Castelló, 2007: 238-239.
} 
en Madrid y comienza sus operaciones el día 30 de septiembre del propio año, después de haber alcanzado los dos millones de pesos en nuevas adhesiones, que les fueron exigidos. Lo que significa que previamente había dejado de funcionar y prueba que se trató de una refundación.

El 20 de noviembre de 1855 se estableció La Protectora, compañía general cubana de seguros mutuos sobra la vida de los esclavos, para indemnizar los casos de muerte e incapacidad por efecto de enfermedad o accidente, con idénticas exclusiones a la anterior. Autorizada por un período de treinta años, se consideraría constituida al lograr asegurar cinco mil esclavos, el seguro se hacía por períodos de cuatro a ocho años, se aceptaban en la póliza esclavos de uno a setenta años empleados en campos y ciudades. Dicha compañía resultó reformada el 7 de febrero de 1858.

En el Museo del Seguro MAPFRE, en Madrid, se encuentra un documento ${ }^{49}$ a través del cual, los señores Lavalle y Cía. domiciliados en calle Cuba n. $^{\circ} 148$ en La Habana, solicitaban protección por cuatro años para una dotación de treinta y una esclavas, ubicadas en el ingenio San Miguel, en Macurijes, que prueba la existencia de la mencionada compañía y del tipo de contrato que ofertaba. El citado documento (acta de adhesión) no es la póliza de seguro; aunque si formaba parte importante del contrato, equivalente a la solicitud actual, donde se incluía la relación de «objetos» asegurados (31 esclavas), así como la evaluación del riesgo.

Aquella no era una póliza colectiva a pesar de que en ella se aseguraba una dotación, porque a cada una se le asignaba un número de póliza diferente. Lo colectivo era la solicitud y el análisis de riesgo, que ahorraba tiempo y esfuerzo a la aseguradora y su agente. Este documento generó una póliza primer día, lo que justifica plenamente el por qué no tiene una fecha determinada, ya que al momento de hacerse el cálculo no se sabía cuándo sería alcanzada la cantidad prefijada, lo que ocurrió el 28 de febrero de 1856. Ello explica el por qué no está redactada en la proforma oficial que la compañía había establecido al efecto, con sus firmas y demás requisitos legales.

\section{Seguros de vida}

El hecho de contar el mercado cubano con aseguradoras de vida del Reino Unido y los EE.UU. resultó de mucha importancia, si se tiene en cuenta que aquellas aplicaban tablas de sus respectivos países, calculadas con mayor rigor científico, aunque desfasadas de la realidad tropical. Los aseguradores

49 Sojo, 2010: 396. Véase http://Ecured.cu/Seguro_de_Esclavos. 
cubanos se beneficiaban de ello al poder, por simple imitación, aplicar tarifas mejor calculadas y por tanto más competitivas, lo que mejoraba su actuación. En Cuba, la primera mención que conocemos de un esfuerzo serio en la confección de una tabla de mortalidad, para ser utilizada en el cálculo actuarial, se remonta a 1895, cuando Andrés Segura Cabrera, publicó su tabla Promedio de Mortalidad en La Habana para el año de 1893.

El 26 de enero de 1855 fue fundada por los señores Ruperto Cid y Miguel de Embil, La Hereditaria, compañía de seguros mutuos sobre la vida, que, autorizada por cincuenta años, entró en operaciones el 31 de marzo ofertando dos modalidades de seguros: para caso de supervivencia y para caso de muerte, sus asociaciones de supervivencia eran de cinco tipos:

1. De aumento del capital con enajenación del capital y de la renta, por entrega única.

2. De aumento del capital con enajenación del capital y de la renta, por entregas anuales.

3. De aumento del capital sin enajenación de la renta.

4. De aumento de la renta sin enajenación del capital.

5. De aumento de la renta con enajenación del capital.

Todas dentro de la modalidad de seguros mutuos a vida entera, la prima se pagaba anualmente y el beneficio lo recibían los asegurados que sobrevivían al finalizar cada quinquenio, según las bases de cada asociación, el aporte de capital realizado individualmente y la tasa de interés pactada. El capítulo IV de los estatutos en sus artículos 26-29 regulaba el reparto de utilidades a los asegurados o sus descendientes, según el caso. La aseguradora fue liquidada el primero de abril de 1861, a consecuencia de la crisis de 1857 y a otras desgracias acaecidas entre las que se cuentan el viaje del director a consecuencia de lo acontecido con su otra compañía, según informó el señor Embil, director de la misma, en carta a Félix Erénchun fechada el 20 de abril de 1861. El gobierno ejercía una función tutelar hacia los asegurados para lograr la credibilidad del sistema empresarial vigente al no permitir la liquidación de la sociedad mercantil antes del período establecido para el reparto de beneficios ${ }^{50}$.

Esta institución no efectuaba actividades bancarias, no aseguraba esclavos ni tenía sus fondos invertidos en La Alianza como suele afirmarse. El primero es un error inducido, probablemente, por la afirmación de J. de La Pezue-

50 Erénchun, 1856, tomo IV: 2412-2424. 
la: «Es una caja de ahorros cuyas operaciones...» $»^{51}$ desconociendo el funcionamiento de aquellas sociedades, los autores posteriores razonarían que si era una caja de ahorro, entonces realizaba operaciones bancarias. El segundo error es por asociar al director de la compañía M. Embil con La Providencia, que sí aseguraba esclavos, lo cual queda claro al ver los estatutos de la compañía. El tercer error es por desconocer que entre las funciones aprobadas a La Alianza estaba la de administrar las fusiones y liquidaciones de otras sociedades mercantiles, por eso al crearse la comisión liquidadora de La Hereditaria los fondos existentes pasaron a la caja de aquella, en calidad de albacea y no como inversión financiera.

\section{Seguros de incendios}

Esta línea ocupaba a la mayoría de las compañías extranjeras. La aseguradora cubana insigne en esta modalidad fue El Iris, que aseguraba los riesgos de incendio, fuego del cielo y explosión de gas. Sus iniciadores fueron los señores José María Morales (primer director), Ruperto Cid y Serapio de Abrogmay, su primer presidente fue José Manuel Espeliux y el vicepresidente, Juan de Dios Larrinaga. A pesar de que todos los trámites se hicieron según lo establecido, estas personas no fueron declarados fundadores porque se trató de una refundación a partir de una compañía anteriormente autorizada (La Mutualidad ${ }^{52}$ en 1852), que no logró entrar en operaciones por no alcanzar la cuota exigida.

La solicitud para su fundación se realizó el 25 de febrero de 1854, autorizada el 20 de enero de 1855 en Madrid y ratificada en La Habana el 20 de febrero de 1855 - sus estatutos fueron publicaron tres días más tarde- entró en operaciones el 25 de abril de 1855, tras alcanzar nueve y un tercio millones de pesos, cifra muy superior a los seis millones exigidos. Aseguraba inmuebles, mobiliario y contenido, dentro de este último se incluían las materias primas, mercancías, insumos, frutos almacenados, utensilios y herramientas, incluso el ganado mayor de la finca asegurada. Cerró el año 1859 con más de cien millones de pesos asegurados en toda la isla: 15,9 de inmuebles; 15,4 de muebles y 71,6 en contenido ${ }^{53}$. Fue la compañía con mayor permanencia en

51 La Pezuela, 1863: 337.

52 Presumiblemente se trató del intento de establecer en La Habana una sucursal de la compañía homónima del Sr. Pikman, fundada en Madrid el 24 de diciembre de 1848. Véase. Madoz, 1849: 395.

53 Erénchun, 1856, tomo IV: 2411. 
el mercado cubano, alcanzando más de cien años de vida comercial al poder sortear los cambios acaecidos y adaptarse a la nueva situación exigida por la administración interventora al comienzo del siglo XX y muy probablemente porque no comercializaba los ramos marítimos y vida, por lo que no interfería con las aseguradoras norteamericanas.

\section{Otros seguros}

Durante la colonia llegaron a fundarse en la isla, otras compañías de seguros que demostraron la capacidad y el entendimiento que se había alcanzado sobre la posibilidad de extender a otros sectores de la economía, el potencial protector del seguro. Estas fueron: La Previsora, compañía de seguros mutuos sobre la vida de los ganados, autorizada el 5 de enero de $1855 ; \mathrm{La}$ Propietaria, compañía de seguros mutuos sobre los alquileres, acreditada el 4 de septiembre de 1856; y La Indemnizadora, compañía de seguros mutuos contra quiebras, aprobada el 11 de octubre de 1856.

El 20 de agosto de 1859 fue autorizada una compañía de seguro para la sustitución de quintos ${ }^{54}$ al pagar una fianza hipotecaria de doscientos mil pesos para garantizar sus operaciones. Fueron sus fundadores los señores Márquez Sterling y Cía., como administrador general fue nombrado Francisco Font. El objetivo de aquella sociedad era poder redimir del servicio militar a los jóvenes con edades comprendidas entre los 10-25 años. Según la propia Ley de Quintas, los jóvenes de veinte a veintidós años estaban sujetos a las quintas para reemplazo del ejército y los de veintidós a veinticinco a los sorteos para ingresar en las milicias provinciales. Apreciándose una notable diferencia con su homóloga española Montepío Universal, que para la misma fecha vendía esta cobertura exclusivamente a niños de hasta catorce años.

\section{COMPAÑías DE SEGUROS EXTRANJERAS}

Hasta los años cuarenta del siglo XIX, si no era súbdito español, se requerían requisitos especiales para poder representar una compañía extranjera dentro del reino, este hecho cambió a partir de 1848, por lo que comenzaron a radicarse sus representantes para vender pólizas a sus coterráneos que negociaban en La Habana, principalmente del Reino Unido, Alemania y los EE.UU.

\footnotetext{
54 Cruz, 2016: 71-72 y 83-84.
} 


\begin{abstract}
Para poder ejercer como comerciante en las colonias españolas, el Código de Comercio de 1829 dejó establecido que todo extranjero residente debía obtener su naturalización como español, aun cuando se siguiera respetando su lugar de origen para otros trámites legales, el individuo en consecuencia debía optar la doble nacionalidad. Después del año 1840 esto se hizo más flexible ${ }^{55}$.
\end{abstract}

El mayor aporte de estas compañías fue la introducción de prácticas más avanzadas, avaladas por los nuevos conocimientos desarrollados en sus respectivos países, como serían los casos de las tarifas de incendios, al estar afiliadas al Fire Office Committee de Londres, que utilizaban la experiencia colectiva alcanzada en los seguros del ramo. En los seguros de vida, al utilizar las nuevas tablas de mortalidad que resultaban cada vez mejores al ser más exactas, por utilizar las nuevas fórmulas desarrolladas.

En 1843 fue publicada en Londres la tabla de mortalidad n. ${ }^{\circ} 1$, Experiencia Combinada, cuya creación había sido acordada el 19 de marzo de 1838 por Charles Ansell (Atlas); Griffith Davies (Guardian); J. J. Downes (Economic); George Kirkpatrick (Law Life); Joshua Milne (Sun); J. M. Rainbow (Crown); W. S. B. Woolhouse (National Loan Fund) y Benjamín Gompertz de la Alliance, bajo la dirección de Robert Christie y al fallecer este, de Samuel Ingall ${ }^{56}$, tabla que gozó de popularidad al ser aplicada en los EE.UU. En el año 1868 fue confeccionada en este último país por Sheppard Homans, primer actuario de la Mutual Life Insurance Company of New York, la tabla Experiencia Americana, basada en la práctica (20 años) de la citada compañía. En 1898 los señores Jones y Robertson, actuarios de la New York Life Insurance Company construyeron una nueva tabla, denominada Experiencia Americana en los Trópicos ${ }^{57}$, aplicando la fórmula de Makeham a la experiencia de esta compañía, todas estas tablas fueron utilizadas en Cuba.

En la realización del artículo se encontró evidencia de al menos cuarenta y dos aseguradoras extranjeras presentes en Cuba en el siglo XIX, incrementándose el número de las reportadas anteriormente, especialmente las inglesas y alemanas ${ }^{58}$ :

\footnotetext{
55 García, 1990: 70.

56 Walford, 1874: 89.

57 Pino, 1953: 99.
}

58 El listado de las aseguradoras extranjeras ha ido elaborado por el autor, basado en Bailly, 1879, Ladd, 1901 y Cruz, 2016. Entre paréntesis se indica primero el año de fundación de la compañía y a continuación el de su establecimiento en Cuba, fecha más antigua confirmada. El asterisco señala las compañías que continuaron operando en la nueva administración, año 1900. 


\section{A. Aseguradoras inglesas}

1. The Sun Insurance Office Company Limited. (1710-1861). *

2. North British \& Mercantile Fire Insurance Company. (1809-1863). *

3. The Northern Assurance Company Limited. (1836-1863). *

4. The London \& Lancashire Insurance Company Limited. (1861-1865). *

5. Phoenix Assurance Company Limited. (1782-1871). *

6. London Guardian Fire and Life Insurance Company Limited. (18211871). *

7. Norwich Union Fire Insurance Society Limited. (1797-1872). *

8. The Liverpool \& London \& Globe Insurance Company. (1836-1878). *

9. Commercial Union Assurance Company Limited. (1861-1879). *

10. Imperial Fire Insurance Company Limited. (1803-1879). *

11. Royal Insurance Company Limited. (1845-1879). *

12. Scottish Commercial Insurance Company Limited. (1865-1879).

13. The Marine Assurance Company. (1866-1879).

14. The Union Assurance Society Limited. (1714-1879). *

15. The Sun Life Assurance Company of Canada. (1865-1892).

16. Law Union \& Rock Insurance Company Limited. (1854-1897).

17. Atlas Assurance Company Limited. (1808-1899). *

18. Law Union and Crown Insurance Company. (n. d. -1899). *

19. London Assurance Corporation. (1720-1899). *

20. Manchester Assurance Company of Manchester. (1869-1899). *

21. Royal Exchange Assurance Corporation. (1720-1899). *

22. Scottish Union and National Insurance Company. (1813-1899). *

\section{B. Aseguradoras alemanas}

1. Nord Deutsche Versicherung Gesellschaft zu Hamburg. (1865-1874).

2. Berlin-Kölnische Feuerversicherung Gesellschaft zu Berlin. (18731879).

3. Frankfurter Glasversicherung Gesellschaft. (1865-1879).

4. Hamburg-Bremer Feuerversicherung Actien-Gesellschaft. (1854-1879). *

5. Hanseatische Feuerversicherung Gesellschaft zu Hamburg. (18731879).

6. Rheinische Versicherung Gesellschaft zu Wiesbaden. (1867-1879).

7. Transatlantische Feuerversicherung AG zu Hamburg. (1872-1879).

8. Transatlantische Güterversicherung Gesellschaft zu Berlin. (1872-1879).

9. Achen-Munich Feuerversicherung Gesellschaft. (n. d. -1899). *

10. Mannheimer Versicherungs Actien-Gesellschaft. (1879-1899). *

11. Preussische National Versicherungs Gesellschaft. (1845-1899). * 


\section{ASEguradoras NORTEAMERICANAS}

1. The Mutual Life Insurance Company of New York. (1843-1843). *

2. New York Life Insurance Company. (1845-1850). *

3. The Equitable Life Assurance Society of United State. (1859-1874). *

4. Germania Life Insurance Company. (1860-1879).

5. United State Lloyd of New York. (1845-1879). *

6. The Fidelity and Deposit Company of Maryland. (1890-1899). *

\section{Aseguradoras SUIZAS}

1. Bâloise Compagnie d'Assurances contre l'incendie. (1863-1879).

2. Schweizer Lloyd ${ }^{59}$. (n. d. -1879).

\section{E. ASEguradora FRANCESA}

1. Comité des Assureurs Maritimes Françaises. (n. d. -1879).

El Reino Unido fue el mayor representado en este segmento de mercado con veintidós compañías, $51 \%$ del total, la mayoría de las cuales vendían cobertura al riesgo de incendio. La compañía Phoenix Assurance procedía de la Phoenix Fire Office; la Imperial Fire Insurance de la Imperial Fire and Life Insurance Co. y The Unión Assurance, de la London Unión Assurance Society Ltd. en el artículo se utiliza el nombre con el cual fueron inscriptas en Cuba.

Era habitual que algunas compañías extranjeras se hicieran publicitar con formas españolizadas de sus respectivos nombres, como fueron los casos de: El Sol de Canadá y la Unión Comercial, ambas del Reino Unido; El Lloyd Americano y La Mutua de Nueva York. Algo que también ocurrió con las aseguradoras alemanas, así tenemos los casos de: Norte Germánica, presente en Holguín hasta 1893; Ansiática de Hamburgo; Rhenania; Trasatlántica de Hamburgo, quienes vendían seguros de incendio y la Trasatlántica de Berlín que ofrecía seguros marítimos.

El reducido número de compañías norteamericanas presentes en esta plaza no es reflejo del alto intercambio comercial que existía entre las dos naciones, ya que, dada la cercanía de sus puertos, las aseguradoras norteñas operaban desde ellos sin ninguna dificultad. Radicándose en La Habana las compañías de seguros de vida, que por razones obvias debían estar cerca de las personas que aseguraban.

Aunque hubo varias compañías cubanas de seguros durante todo el siglo XIX, las extranjeras, por su permanencia y capacidad técnico-financiera, do-

59 El Lloyd Suizo representaba, en San Ignacio 78 (altos), las compañías Bâloise, Rhenania y Frankfurter. Véase Bailly, 1879: 1539. 
minaron el mercado nacional en todos los ramos, con la excepción del seguro de esclavos.

\section{Fin DEL SEGURO ESPAÑOL EN CUBA}

En el último cuarto del siglo se continuaron creando compañías cubanas de seguros como La Humanitaria (1888), El Fénix (1891), el Círculo Cosmopolita (1895) y La Unión Antillana (1899), esta última ya en la nueva administración. En la mayoría de los casos surgidas para reemplazar las compañías extintas, que duraban poco tiempo en el mercado, debido a sus escasos recursos técnicos y financieros.

La guerra de independencia librada en Cuba contra la metrópolis colonial provocó un importante descenso en la producción de azúcar, la cual bajó de un millón ciento once mil toneladas en 1894 a novecientos ochenta y tres mil en 1895; doscientos ochenta y seis mil en 1896; doscientos setenta y un mil en 1897 y doscientos cincuenta y nueve mil en $1898^{60}$, esta deflación del $66 \%$ ocasionó la caída del volumen de operaciones en la exportación del azúcar, afectando proporcionalmente el mercado de seguros de la isla. En 1896, transcurrido un solo año de guerra, se reportaron 96 ingenios destruidos: 29 en Pinar del Río; 25 en La Habana; 31 en Matanzas; 9 en Santa Clara; y 2 en Santiago de Cuba ${ }^{61}$, de los cuales, diez fueron demolidos. La segunda tabla recoge las pérdidas de aquel año, excluyendo los gastos de la deuda pública.

Tabla 2. Perjuicios ocasionados A LA ECONOMÍA EN 1896

\begin{tabular}{|l|c|c|}
\hline \multicolumn{1}{|c|}{ Pérdidas reportadas durante el primer año de guerra } & Pesos & $\%$ \\
\hline Por daños a la producción azucarera. Campo e industria. & 69500000 & 47,76 \\
\hline Por daños a la producción tabacalera. Campo e industria. & 20000000 & 13,75 \\
\hline Por la destrucción de propiedades particulares y del gobierno. & 21000000 & 14,43 \\
\hline Por la disminución de valores públicos. & 20000000 & 13,75 \\
\hline Por la paralización de negocios. & 15000000 & 10,31 \\
\hline Total. & 145500000 & 100,00 \\
\hline
\end{tabular}

Fuente: elaborada por el autor, basado en Iglesias, 1999.

\footnotetext{
60 Moreno, 1978, tomo III: 35-40.

61 Iglesias, 1999: 165.
} 
Aunque hubo pérdidas en toda la economía, fue la azucarera, la que más se afectó a causa de la guerra (48\%). Las vías férreas, las locomotoras e ingenios destruidos, así como, la pérdida de caballos y mulos, requerirían de una fuerte inversión y tiempo para reponerse. La pérdida de animales representó un daño importante a la hacienda azucarera y por tanto a la industria en general, porque afectaba tanto las labores rutinarias de carga y transportación, así como la obtención de alimentos. Se reportó la pérdida de 2837790 animales de valor (vacuno, caballar, mular, porcino y ovino), que representaban el $76,5 \%$ de los preexistentes en $1891^{62}$.

Cuando el 16 de julio de 1898 España depuso sus armas en Santiago de Cuba ante el ejército interventor norteamericano, terminaba formalmente el coloniaje en Cuba y con ello la actividad del seguro, tal y como había sido concebida a imagen y semejanza del español. Se habían perdido ya la mayoría de las compañías cubanas de seguros, por ser las de menor capacidad financiera; sin embargo, la mayoría (64\%) de las compañías extranjeras continuó operando. Porque pudieron mantener su cuota de mercado, que respondía mayoritariamente al intercambio mercantil que sus coterráneos continuaban teniendo con el gobierno de la isla; porque tenían el respaldo de sus casas matrices y porque se vieron favorecidas por la administración interventora, que a través de la orden n. ${ }^{\circ} 181$ del 27 de septiembre de 1899 modificó la cuantía de las garantías que debían aportar las aseguradoras a la tesorería, disminuyendo los doscientos mil pesos que tenían establecido a setentaicinco mil las de incendio y a veinticinco mil las demás, creando de paso tres nuevos ramos: riesgo y accidentes, caución y fianzas ${ }^{63}$.

El mercado de seguros en Cuba concluyó el siglo XIX con 29 aseguradoras, dos sociedades cubanas -El Iris y la Unión Antillana- y 27 compañías extranjeras: 4 alemanas, 5 norteamericanas y 18 británicas. Solo tres de las británicas no habían cubierto su aporte totalmente para el 30 de junio del año 1900, ellas fueron: North British, Northern Assurance y Phoenix Assurance. Dicha garantía se aportaba en bonos de La Habana y/o del tesoro de los EE.UU. y/o en acciones de las compañías: Ferrocarril Central, Ferrocarril Occidental y Almacenes de Regla. Pagados indistintamente en oro español y/o libra esterlina y/o dólar norteamericano ${ }^{64}$.

\footnotetext{
62 Ibidem, 2005: 100.

63 Brooke, 1900: 103-104.

64 Ladd, 1901: 54.
} 


\section{ConClusiones}

Conocer la historia del mercado de seguros es una forma práctica de entender las relaciones de producción dominantes y el comercio, en un período determinado, lo que permite a su vez obtener una mejor imagen de la economía del país. Este artículo es apenas un acercamiento al mercado de seguros en la isla de Cuba durante el siglo XIX, algo que evidentemente requiere de mayor investigación.

El estudio realizado demuestra la existencia de un mercado de seguros en la isla durante el siglo XIX, el cual tuvo sus propias características, fruto de su nacionalidad e idiosincrasia, permitiendo una adecuación a las condiciones de la isla. Constatándose en él que, aun cuando estaba regido por los mismos principios administrativos, no era exactamente igual al existente en la península. En el artículo se reporta la presencia de 78 sociedades de seguros, el doble de las reportadas anteriormente ${ }^{65}, 36$ españolas (22 fundadas en La Habana) y 42 extranjeras (Reino Unido 22; Alemania 11; EE.UU. 6; Suiza 2; Francia 1). Las británicas y las alemanas tuvieron la primacía numérica, contribuyendo de diferentes maneras al incremento técnico del seguro nacional. Lo expuesto ratifica a Cuba como el primer país latinoamericano en tener una institución agrupadora del seguro y el segundo en fundar su primera aseguradora.

Hubo a mediados del siglo XIX un boom fundacional de compañías de seguros que, junto a las instituciones de crédito también creadas, pretendieron asentar las condiciones para un engrandecimiento material de la sociedad cubana que en parte se vio frustrado por la crisis monetaria de 1857. Demostrándose que otras necesidades de protección financiera se podían solventar a través de la transferencia del riesgo, algo explícito en las nuevas líneas de seguros que pretendieron introducir al mercado, aun cuando algunas de ellas no lograron su cometido.

El hecho de haber tenido La Habana un mercado de seguros tan activo, con la presencia de tantas aseguradoras extranjeras, solo puede sugerir que la ciudad fue una próspera plaza, con un alto intercambio mercantil y financiero. Al ser el mercado de seguros un reflejo de la economía, no podía quedar indemne ante la caída del sistema que lo sustentaba, por eso, al caer el colonialismo en Cuba, producto de la Guerra de Independencia, deja de funcionar. Sin que esto signifique una falta de aportes a este sector de las finanzas, ya que, en esta primera centuria, se produjo tal acumulación de conocimientos

\footnotetext{
65 Cruz, 2016: 8.
} 
prácticos, que sin dudas contribuyeron a enriquecer el acervo técnico-jurídico que se alcanzaría en el siguiente siglo, cuando las finanzas así lo demandaron. Conocimientos obtenidos principalmente de las aseguradoras extranjeras operantes, que aplicaban ya las más avanzadas prácticas de aquel momento, sumando a esto, el innegable aporte nacional.

El cambio de administración no representó un serio obstáculo para la permanencia de la mayoría de las aseguradoras extranjeras en la plaza, más bien todo lo contrario, pues su permanencia a inicios de la administración interventora era del $83 \%$ para las norteamericanas; $82 \%$ para las británicas y $36 \%$ para las alemanas, que resultaron ser las perjudicadas (alejadas de la nueva administración) ya que, con el nuevo reparto de la cuota de mercado, en poco tiempo fueron excluidas.

El seguro cubano del siglo XIX no llegó a modernizarse porque el modelo a seguir, el español, tampoco lo hizo y porque seguramente la administración colonial no lo habría permitido. Además, las compañías cubanas operaban con escaso capital, sin tablas de mortalidad propias y eran víctimas de un fuerte intrusismo gubernamental. La falta de una legislación propia, Ley del Seguro, que individualizara y protegiese esta industria en España ${ }^{66}$, sin duda, contribuyó a su tardío desarrollo, afectando también al mercado cubano. El saldo del seguro en la isla, no obstante, fue positivo, porque se incrementó la utilización de esta técnica de administración de riesgos y en diversas situaciones prácticas demostró su valía.

\section{Citas BIBLIOGRÁFICAS}

Almanaque universal de la correspondencia de España o Guía general de Madrid y de las provincias para el año 1861, Madrid, Imprenta de la correspondencia de España, 1860.

Anuario estadístico de España 1858, Comisión de Estadística General del Reino, Madrid, Imprenta Nacional, 1859.

Araujo de Lira, José, Carta sobre el estado político y económico de la isla de Cuba en 1849, La Habana, Imprenta del Diario de la Marina, 1850.

66 Finalmente, la Ley fue aprobada el 14 de mayo del año 1908, conocido como el «Año de oro» del seguro español, por eso cada año se celebra en esa fecha el Día del Seguro Español. Coincidentemente, en América se celebra en la misma fecha el Día del Seguro Continental, debido a que ese día de 1946 comenzó la primera Conferencia Hemisférica de Seguros, la que continúa efectuándose cada dos años. 
Bailly, Carlos, Anuario almanaque del comercio, de la industria, de la magistratura $y$ de la administración, Madrid, Editor Bailly-Bailliere, Año I, 1879.

Barnes, Williams, Seventh Annual Report of the Superintendent of the Insurance Department, Albany, Cornelius Wendell Legislative Printer, 1866.

Benito y Endara, Lorenzo, Derecho Mercantil de David Supino, Traducido de la 4ta edición (italiana) y anotado extensamente con las diferencias del derecho español, Madrid, La España Moderna, 1895.

Brooke, John, Civil Report of Major-General John R. Brooke U.S. Army, Military Governor, Island of Cuba, Washington, Government Printing Office, 1900.

Calendario manual y Guía de forasteros de la isla de Cuba para el año de 1795, La Habana, Imprenta de la Capitanía General, 1795.

Cantero, Justo Germán, Los ingenios, colección de vistas de los principales ingenios de azúcar de la isla de Cuba, La Habana, Litografía de Luis Marquier, 1857.

Cruz Pasos, Rosell, Hitos del seguro en Cuba, Saarbrüken, EAE OmniScriptum GmbH \& Co. KG., 2016.

Erénchun de Medrano, Félix, Anales de la isla de Cuba. Diccionario administrativo, económico, estadístico y legislativo. Año 1855, La Habana, Imprenta La Habanera, 1857-1861.

Galiano, Dionisio A., Cuba en 1858, Madrid, Imprenta de Beltrán y Viñas, 1859.

Gallardo, Diego, Almanak mercantil o guía de comerciantes, Madrid, Imprenta de la viuda de Joaquín Ibarra, 1796 y 1799; Madrid, Imprenta de Vega y Compañía, $1802,1803,1805$ y 1808.

García Álvarez, Alejandro, "Prólogo", Fe Iglesias, Del Ingenio al Central, La Habana, Editorial Ciencias Sociales, 1999.

García Rodríguez, Mercedes, “El sector comercial en las matrículas de 1833”, Revista Biblioteca Nacional José Martí, 40/23 (La Habana, 1990): 65-88.

García Rodríguez, Mercedes, La aventura de fundar ingenios, La Habana, Editorial de Ciencias Sociales, 2004.

Guerra Sánchez, Ramiro, Manual de historia Cuba, La Habana, Editorial Pueblo y Educación, 1989.

Guerra Sánchez, Ramiro, Pérez, José, Remos, Juan y Santovenia, Emeterio, Historia de la nación cubana, La Habana, Editorial de la Nación Cubana, 1952, 10 tomos.

Iglesias García, Fe, Del ingenio al central, La Habana, Editorial Ciencias Sociales, 1999.

Iglesias García, Fe, Economía del fin de siglo, Santiago de Cuba, Editorial Oriente, 2005.

La Pezuela, Jacobo de, Diccionario Geográfico, Estadístico, Histórico de la isla de Cuba, Madrid, Imprenta del establecimiento de Mellado, 1863, vol. III. 
La Pezuela, Jacobo de, Historia de la isla de Cuba, Madrid, Editor Bailly-Bailliere, 1878 , vol. III.

La Sagra y Peris, Ramón Dionisio de, Cuba en 1860. Cuadro de sus adelantos en la población, la agricultura, el comercio y las rentas públicas, París, L. Hachette y Cía., 1862.

Ladd, Eugene F., "Report of treasurer of the island of Cuba", Leonard Wood (coord.), Reports of the Military Governor of Cuba on Civil Affairs, for de fiscal year ended June 30, 1900, Washington, Government Printing Office, 1901, vol. I, part 3th: 29-82.

Le Riverend Brusone, Julio, Historia económica de Cuba, La Habana, Editorial Pueblo y Educación, 1981.

Madoz, Pascual, Diccionario Geográfico-Estadístico-Histórico de España y sus posesiones de ultramar, Madrid, Imprenta del Diccionario geográfico-estadístico-histórico de Pascual Madoz, 1849, tomo XIV.

Mascarós, Julio, Historia de la Banca en Cuba (1492-2000), La Habana, Editorial Ciencias Sociales, 2004.

Moreno Fraginals, Manuel, El ingenio: complejo económico social cubano del azúcar, La Habana, Editorial Ciencias Sociales, 1978, 3 tomos.

Ortega, Virgilio, "Hacia una Amplia Política de Cooperación Recíproca entre Aseguradores de América Latina”, Revista Seguros, 8/82 (La Habana, 1943): 30.

Pino Quintana, Ernesto, Matemáticas financieras, La Habana, Pueblo y Educación, 1953.

Pons Pons, Jeronia y Pons Brías, María Ángeles (coord.), Investigaciones históricas sobre el seguro español, Madrid, Fundación MAPFRE, 2010.

Roldán Montaud, Inés, La banca de emisión en Cuba (1856-1898), Madrid, Editado por el Banco de España, 2004.

Sojo Gil, Ana, Museo del seguro, Madrid, Fundación MAPFRE, 2010.

Tablada, Carlos y Castelló, Galia, La historia de la banca en Cuba. La colonia, La Habana, Editorial Ciencias Sociales, 2007.

Torres, Manuel, Bibliografía española contemporánea del derecho y de la política. 1800-1880, Madrid, Librería de Don Fernando Fe, 1883, vol. I.

Tortella Casares, Gabriel, Caruana de las Cagigas, Leonardo, García Ruíz, José, Manzano Martos, Alberto y Pons Pons, Jerónia, Historia del seguro en España, Madrid, Fundación MAPFRE, 2014.

Vigil Iduarte, Alejandro, "Esbozo histórico del seguro en Cuba. Etapa colonial", Revista RIS, 32/19 (Bogotá, 2010): 59-72. 
Walford, Cornelius, The Insurance Cyclopcedia, London, Printed by Charles and Edwin Layton, 1874, vol. III.

Yáñez Gallardo, César, "Los negocios ultramarinos de una burguesía cosmopolita. Los catalanes en las primeras fases de la globalización, 1750-1914", Revista de Indias, LXVI/238 (Madrid, 2006): 679-710.

Fecha de recepción: 12 de julio de 2017.

Fecha de envío de las modificaciones: 19 de septiembre de 2017.

Fecha de aceptación: 22 de septiembre de 2017.

\section{The insurance market in Cuba in nineteenth century}

The present article confirms the existence of an insurance market in Havana during the nineteenth century, comprising 78 insurance companies operating in this marketplace: 36 were Spanish (61\% of which were founded in Havana) and 42 from other countries, duplicating previously accepted estimates. The study is corroborated by an exhaustive review of documents published while the events narrated were taking place, including the official data sent to the Overseas Ministry and legal provisions issued by the island's governors. Also examined are subsequent publications dealing with events that influenced the development of the sugar industry and trade on the island. This development in turn drove the need for insurance to shore up that economic venture.

KEY WORDS: Insurances market; Cuba; Insurance Companies; nineteenth century. 